\title{
A JOURNAL ON
}

\section{PRIMARY HEALTH GARE}
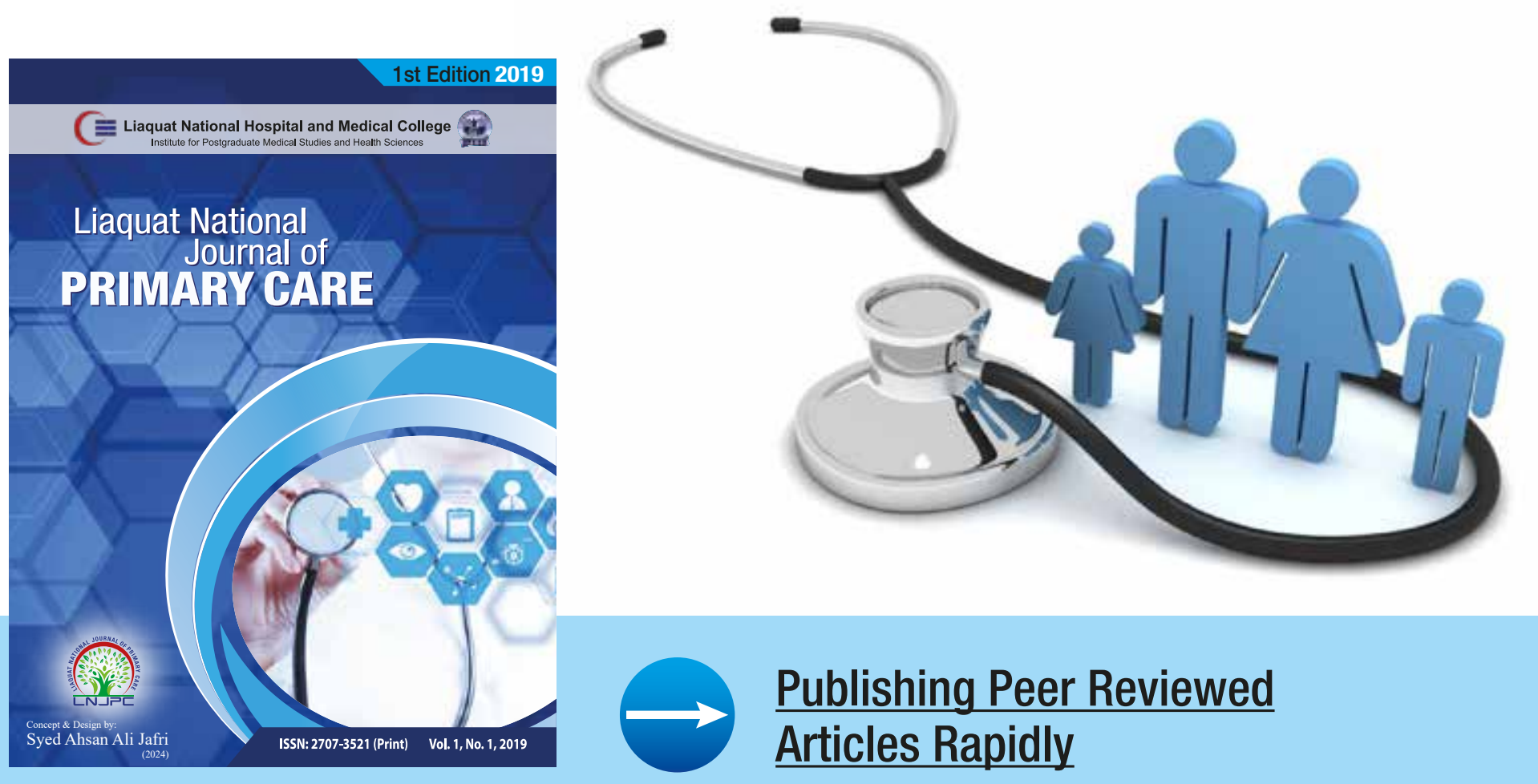

\section{Editor-in-Chief: \\ Prof. Dr. Karimullah Makki Karachi, Pakistan}

The Journal aims to focus on recent developments is primary health care in Pakistan and elsewhere.

\section{$\rightarrow$ Available in Print \& Online}

\section{For Submission:}

https://journals.Inh.edu.pk/JMS

For Information:

www.Injpc.edu.pk

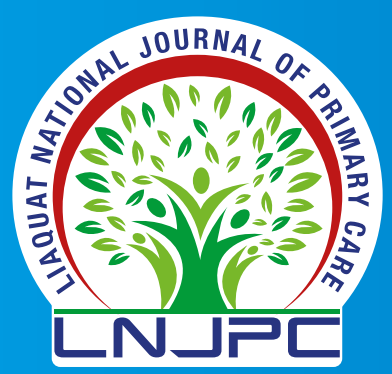

